\title{
IoT based a Smart Home Automation System Design: Simulation Case
}

\author{
Erdal Ozdogan, Resul Das
}

\begin{abstract}
Today, solutions developed with the Internet of Things have started to find more and more application areas to make human life easier. Internet of Things solutions, which include many different types of new technologies, will be very useful to use simulation tools before prototyping for the most appropriate technology selection. In this study, IoT-based smart home design applications have been developed and analyzed. In this context, 3 different scenarios have been developed for smart home automation system design in the Cisco Packet Tracer simulation environment, and the use of tools has been demonstrated with examples according to different scenarios.
\end{abstract}

Index Terms-Smart home automation, IoT solutions, Packet tracer, Simulation, Internet of Things.

\section{INTRODUCTION}

W ITH THE spread of the Internet of Things (IoT), Smart Home Automation systems are increasingly being applied. By 2023, the smart home market is expected to reach \$ 141.2 billion, an increase of $17 \%$ compared to 2019 [1]. In addition to the existence of many commercial applications in smart home automation, application developers also develop home automation systems using various tools. On the other hand, the widespread use of Internet of Things technologies has caused home users to develop their own solutions with various hardware. The widespread use of microcontrollers (MCU) or single board computers (SBC) has been effective in the implementation of IoT systems in the home environment. Many different numbers and types of IoT systems are used for various purposes in home automation systems. However, this rich diversity requires understanding of many components in the development of IoT-powered home automation systems. Evaluating different products during the testing phase of the developed system causes additional labor and time loss. Prototyping on a large scale using a large number of hardware may not be practical at the design and evaluation stage due to economic and operational constraints, especially when the reliability and usefulness of the protocol in question has not yet been proven [2]. In addition, preparing the physical components for the connection and use of the connections prevents the focus from the solution. The use of simulation software will be beneficial in IoT ecosystem design due to

ERDAL ÖZDOĞAN is with the Ministry of National Education, General Directorate of Basic Education, Ankara - TURKEY e-mail: erdalozd@gmail.com

(iD) RESUL DAS is with the Department of Software Engineering, Technology Faculty, Firat University, Elazig, 23119 TURKEY e-mail: rdas@ firat.edu.tr

Manuscript received April 17, 2021; accepted July 26, 2021.

DOI: $10.17694 /$ bajece. 918826 the advantages of using an unlimited number of devices, focusing on the solution to be developed, and also posttest before prototyping. Multiple technologies, device types, protocols and infrastructures are used in the development of IoT solutions. The IoT solution developed in such a complex situation requires many testing processes and methods to achieve the desired benefit. The use of simulation software in the development of IoT solutions will allow to focus directly on the intended test item and separate test items from other complex situations. In this study, it will be discussed how to use simulation tools effectively in the development of IoT supported home automation system, what advantages it will offer in creating prototypes, and a simulation-supported systematic approach is proposed to develop an IoT Home automation system. In the following parts of the study, IoT supported home automation systems, software and hardware used in this system will be explained. In addition, sample scenarios and solutions including different hardware types will be simulated for simulation-supported system development.

\section{RELATED WORK}

Electronic equipment used in today's traditional home environments is generally hardware that works independently from each other. The purpose of home automation systems is to create smart environments by ensuring the interoperability and integration of these independent equipment. With IoT support, home automation becomes more capable and makes human life easier. IoT-supported home automation systems have become increasingly popular in recent years, and many academic studies have been done on this subject. Academic studies cover many different fields from security, technology, architectural design to energy efficiency due to the multidisciplinary nature of IoT. In particular, many different IoT solutions have been developed for elderly and disabled people in the field of health, and there are many applications in the literature [3], [4], [5] In a study aimed at integrating the functions of different home automation devices into a single application, a modular smart home solution was developed to connect more devices and manage them remotely [6]. In the study by T. Malche and P. Maheshwary [7], an IoT-supported smart home system was designed to remotely monitor and control home environments. In the mentioned study, applications such as smart lighting, gas detection and intrusion detection were carried out using Arduino hardware. H. Singh et al. developed a new solution that used a variety of sensors to control some home appliances such as light, fan, door, energy consumption and gas level [8]. In this solution, a system consisting of 
system design, objectives and implementation details is also proposed. In another study on IoT powered home automation system design, a design methodology and an Arduino based application were developed by W.A. Jabbar et al. [9]. In the study of F. Yalçınkaya et al., the MQTT based smart home system was designed and evaluated in three different scenarios [10]. In the study of Ö.Sine and Y. Koçyiğit, an automation system that can be controlled over the internet was designed and its usage areas were specified in various application scenarios [11]. The study of Güneş et al, developed with the support of artificial intelligence, simulated a home environment consisting of thermostats, sockets and lamps in each of the three rooms. In the study, it was proposed to develop a simulation that includes different components [12]. In Eleyan and Fallon's study, an MQTT-based automation system was designed for individuals with special needs and people with physical disabilities [13]. In H. Nguyen-An et all's study, it was stated that there are a wide variety of IoT devices for different purposes in smart home environments and that the traffic generated from these devices has a strong effect on IoT. In the study, it was stated that the features of IoT traffics are not known enough and the importance of analysis is emphasized and that these traffics are produced synthetically [14]. In the study of M. Assim and A. Al-Omary, a design was made for the smart home environment using Packet Tracer simulation software and then a prototype was produced [15].

As can be seen in the related study, home automation systems have been developed using different sensor types, MCU and SBC hardware. However, these studies are limited because they examine smart home IoT devices in test environments or on a small scale. Since the majority of applications are geared towards a specific solution, they only show a part of home automation systems. Whereas, in simulation software, largerscale applications can be developed thanks to the ability to add more devices and types.

\section{IoT based Smart Home Automation}

Home automation solutions are systems that consist of hardware that can communicate with each other and components that can be accessed remotely via web environment or mobile devices [15]. In other words, these systems are an example of an IoT ecosystem that requires the use of hardware, software and network infrastructure together. Because of the complexity that IoT brings, designing a home automation system becomes extremely important. The problems that IoT systems try to find solutions to are generally based on smart city applications and smart campus applications. IoT Home Automation systems can also be considered as small prototypes of these solutions. For this reason, IoT Home Automation Systems, which are correctly designed, tested and proven to be useful, will contribute to the formation of smart cities. Home automation systems, which are basically an IoT solution, consist of hardware, software / application and communication protocol components in accordance with the three-layer IoT architectural approach [16]. Each of these components are equally important components in designing an effective system. Different hardware components and communication protocols can be used for various purposes. It may be necessary to evaluate multiple hardware, applications and protocols during design to reach the correct and optimum solution. Using simulation programs for IoT Home Automation Systems will provide an accurate assessment. Many advantages offered by IoT have contributed to the development of home automation systems [17] . The usefulness of home automation systems is directly related to the capabilities of IoT components. Below are some examples of IoT powered home automation systems:

- Intelligent lighting

- Air conditioning

- Garden management

- Motion sensitive home security systems

- Air / Water quality monitoring

- Intelligent lock systems

- Smart Energy Management

Apart from these examples, there are different application areas with the developing technology. However, it needs to be defined to help create a realistic model of which main components are involved in building a smart home automation.

\section{A. IoT based Smart Home Automation System Components}

Home automation systems are IoT supported applications that provide customization by controlling the living and working environment. These solutions usually consist of actuators and sensors. These are applications that provide the comfort and safety of people without user intervention [1]. In such applications, human-machine communication $(\mathrm{H} 2 \mathrm{M})$ can be provided by connecting to the devices in the house over the internet, as well as Machine-Machine (M2M) communication that triggers an alarm according to the value of the smoke detector. Sensors play an important role in both M2M and H2M communication [18]. Various sensor types that have been used in the industry for many years have taken their place in home automation systems with the widespread use of IoT the most common types of sensors are temperature sensor, light intensity sensor, water level sensor, and sensors that detect various gases in the air. Apart from these, various sensor types such as pressure, acceleration, humidity, infrared, vibration, flexibility, ultrasonic distance and sound sensor can be used in IoT Home Automation systems. These sensors used in applications are generally hardware with no computational capability or low computational capacity [2]. Also, many sensors do not have the ability to connect a etwork. Therefore, there is a need for components in the network, called IoT Gateways, that enable the transfer of digital or analog information received from sensors [19]. The IoT Gateway is a component that takes the properties of the physical world such as temperature, humidity, light intensity through sensors and is responsible for processing the received data and placing it in Internet Protocol (IP) packets. Another function of the IoT Gateway is the ability to send commands to actuators to perform various actions under conditions specified by programming. Although there are many different types and capabilities of IoT Gateway hardware in the industry, the most common characteristics of these devices are to provide wired or wireless connections and to establish an internet 
connection. Microcontrollers (MCU) such as Arduino and single board computers (SBC) such as Raspberry-Pi are used for this purpose in small-scale applications and prototypes. Figure 1 shows a section of the basic components commonly used in smart home automation systems.

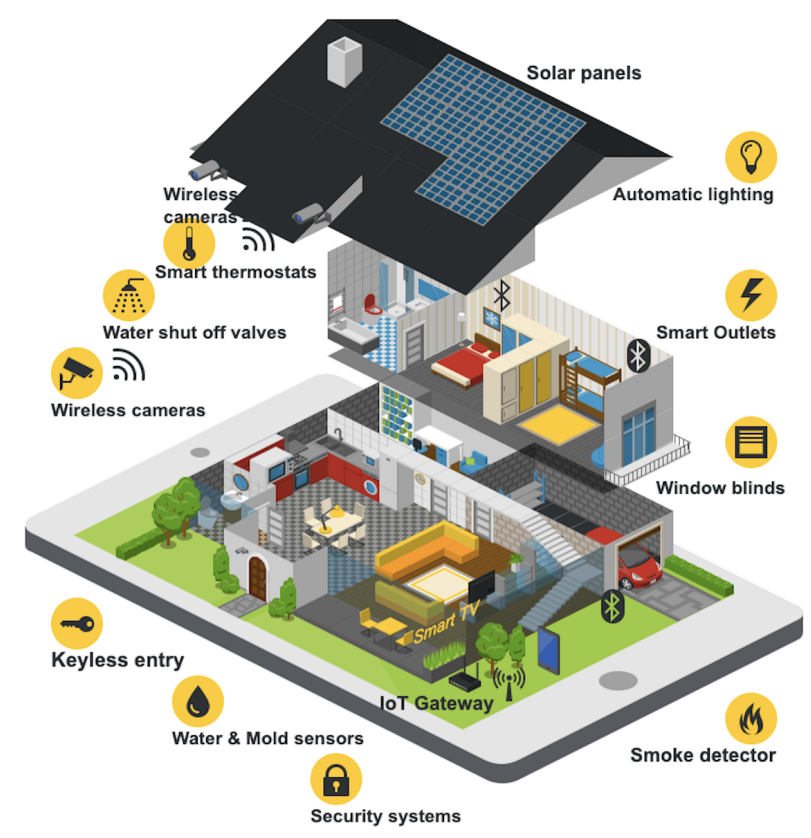

Fig. 1. A view from the smart house

Within the scope of this study, MCU and SBC equipment will be used in simulation environments regardless of manufacturer and brand. Thus, it will be possible to focus directly on system solution development without focusing on manufacturer and model-based differences.

\section{B. IoT Communication Protocols}

One of the most important issues to be considered in home automation system development is determining the communication protocol. Communication protocols are application layer protocols that allow data to be transported in IP packets over the network. Different communication techniques are used in the development of IoT solutions. In the classification of IoT communication protocols, it can be seen that there are protocols communicating via a central server (publish/subscribe method) and protocols that communicate directly without an intermediary server (request-response method) [20]. MQTT, which is the most used protocol in the development of IoT solutions, is a TCP-based IoT application protocol that works in the broadcast / subscriber architecture [21]. Internetbased MQTT resources can be used at the stage of designing a home automation system prototype [10]. Various licensed or free resources are available for this purpose. Also, local applications running on SBC hardware can be used. Another protocol used in IoT applications is the CoAP protocol that runs on the Request / Response architecture [22]. The advantage of the CoAP protocol is that on-demand queries can be made directly through the IoT Gateway without requiring an additional server. In this way, the bandwidth consumption is reduced since there will be no need for periodic publishing. Another method that is becoming increasingly common in the development of IoT solutions is the use of REST API [23]. This method, like CoAP, is in a request-response architecture that provides low overhead over http messages. REST API is a programming interface that runs over http and works on the principles of the http protocol. The IoT Gateway can be directly communicated via REST-API and the value obtained from the sensor can be queried. Determining the most suitable protocol in IoT solutions is directly related to the purpose of the developed solution. In addition, evaluation criteria such as data transfer rate, security level, network topology, type of data transmitted and query frequency, distance should be taken into account. The ability to change these values easily in the simulation environment will contribute to the selection of the correct suitable protocol. Internet of Things protocols can be divided in three groups: infrastructure protocols, service discovery protocols and application protocols. The layout of these protocols in OSI layers is shown in the Fig. 2.

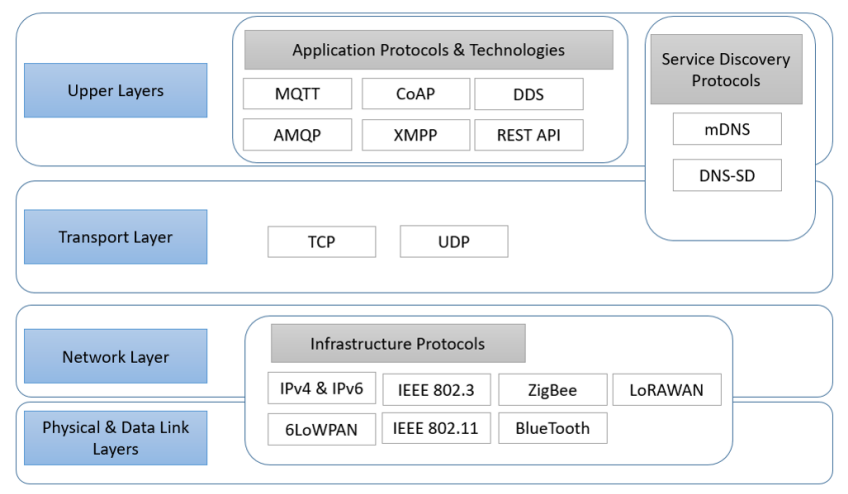

Fig. 2. IoT protocols

\section{Simulation Supported Home Automation System Design}

Within the scope of this study, a phased approach consisting of six steps shown in Figure 3 is proposed in the design of the simulation-supported home automation system.

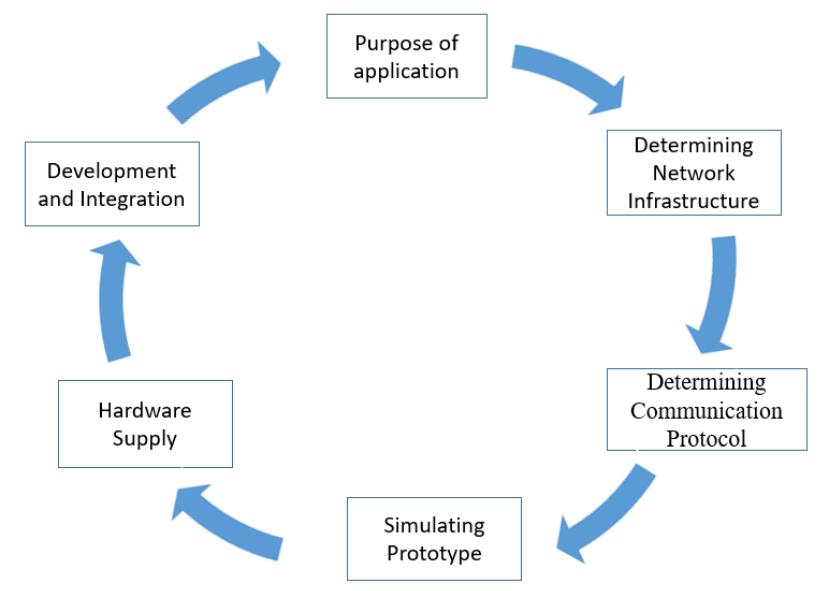

Fig. 3. Simulation-supported IoT solution design steps 
At the stage of determining the purpose of the application, the purpose of the IoT solution to be developed is determined. Examples such as the motion-sensitive home security system and the air conditioning of the living area are determined at this stage. Determination of network infrastructure and technologies; The networks and technologies needed are determined according to the purpose of the problem. At this stage, it is determined which technologies such as NFC, Bluetooth or ZigBee to be used in wired or wireless infrastructure, sensor - IoT Gateway communication. At this stage, it is determined whether the communication will be kept locally or whether cloud services will be used. Local storage and communications can be used when there are concerns regarding the security of cloud Technologies [24]. Determining communication protocol; At this stage, the communication protocol to be used is determined according to the targeted purpose and network infrastructure. If there is a periodic query and a high bandwidth requirement, publish / subscribe protocols can be used, otherwise, REST-API or CoAP can be used. Simulating the prototype; According to the purpose and technology determined in the previous stage, the prototype to be developed in the simulation software is simulated. According to the problems encountered, changes can be made in the previous stages, or if the simulation result is successful, the next stage can be passed. At this stage, it is evaluated again whether the used bandwidth is calculated and the communication protocol works efficiently and in accordance with the purpose. Provision of necessary hardware: After the success of the previous stage, the hardware used in the simulation is provided. The solution developed during the development and integration phase of the system is implemented. At this stage, a new system or integration to an existing system can also be made.

\section{Sample Simulation Scenarios}

Within the scope of this study, sample IoT solutions will be developed using Packet Tracer simulation software over sample scenarios.

There are many types of sensors that can be used in IoT applications in simulation software. These tools are shown in Figure 4. In addition to these tools, various actuators are shown in Figure 5. In Packet Tracer simulation software, advanced IoT systems can be developed using Python, Java Script or microcontroller and single-board computer hardware that can function as an IoT Gateway with block-based visual programming capability.

1) Sample scenario - 1 (M2M Sample): In the home automation system, there is a need to take the temperature values in various locations and generate an alarm for the positions far above the average value and send an IP packet to a specific location. The topology of this scenario in which ${ }^{2}$ the wired infrastructure is used is shown in Figure 6. Data ${ }_{2}^{2}$ will be sent to the server with 192.0.2.10 IP address in the internet environment in the topology. In the example scenario, 4 temperature sensors located in different locations were connected to the MCU hardware and the temperature of the location where a sensor is located was consciously increased.

Pre-existing Python codes in the simulation were changed according to the scenario, and the value that deviated from the averaging from the MCU device was sent to the server using the UDP protocol. It is provided to receive the package sent by using Python codes on the server. Python codes in both hardware are shown in Figure 7.

2) Sample scenario - 2: There is a need to subscribe to the status of a sensor and send data to the MQTT broker using the MQTT protocol. The sample simulation topology for the scenario is shown in Figure 8.

In this scenario, the garage environment where the smoke sensor associated with the SBC is located will be checked periodically. SBC will work as the MQTT Publisher and report the smoke amount to the MQTT broker (192.168.1.100) with the "Home/Garage" topic at 60 second intervals. The tablet computer used by the home user is in the MQTT subscriber role and subscribed to the "Home/Garage" topic via the MQTT server. The subscription of the tablet computer to the relevant topic and the message sent from the publisher via the MQTT broker are shown in Figure 9. One of the advantages offered in the simulation program is the advantage of using ready-made MQTT python codes. In this way, MQTT based applications can be used without focusing on the coding feature.

3) Sample scenario - 3: A home with an IoT Gateway component from a specific manufacturer needs multiple contingent, customizable IoT solutions. Sample simulation topology for the scenario is shown in Figure 10. In this scenario, the energy needs of the lamp and coffee machine in the house are met by the battery by using the solar panel. Besides, the IoT Gateway device controls all components in the home automation system. When the smoke level rises above 10 units through the MCU, it will open the house door, garage door, window, and turn on the fan. The corresponding JavaScript codes in the MCU device are shown below.

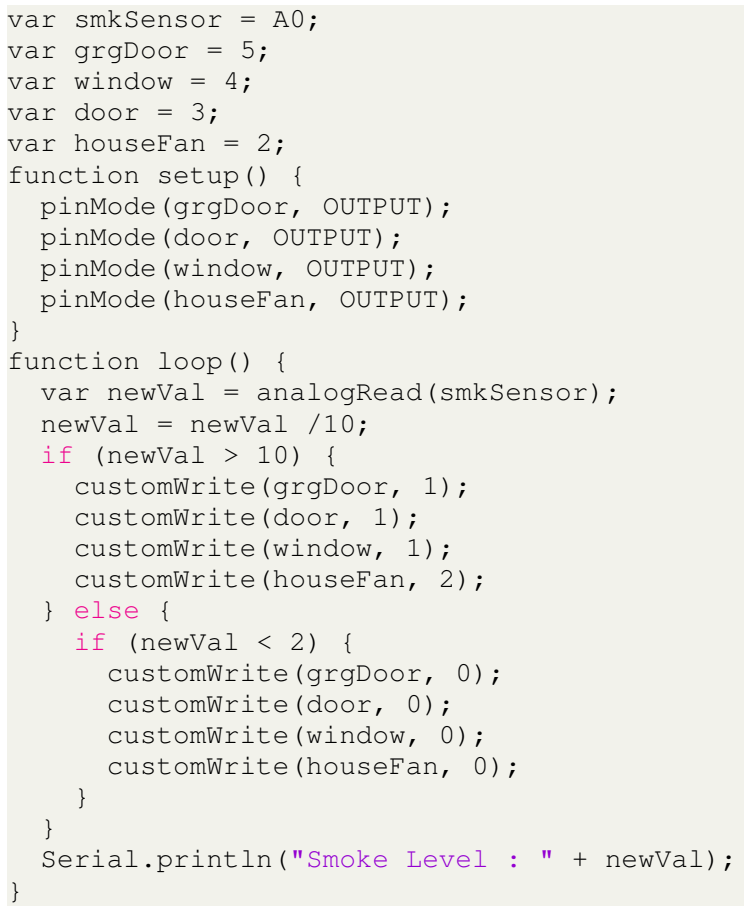




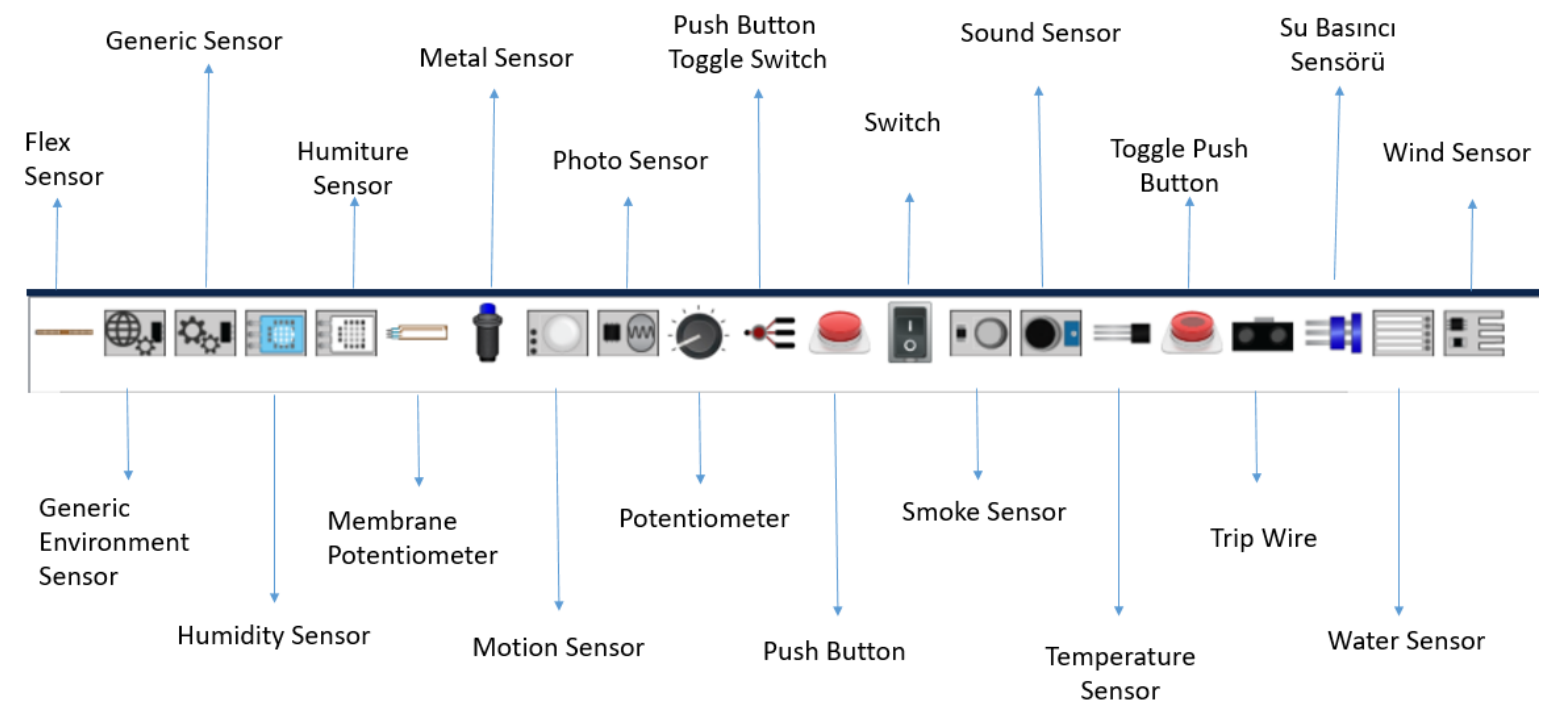

Fig. 4. Sensors in simulation software

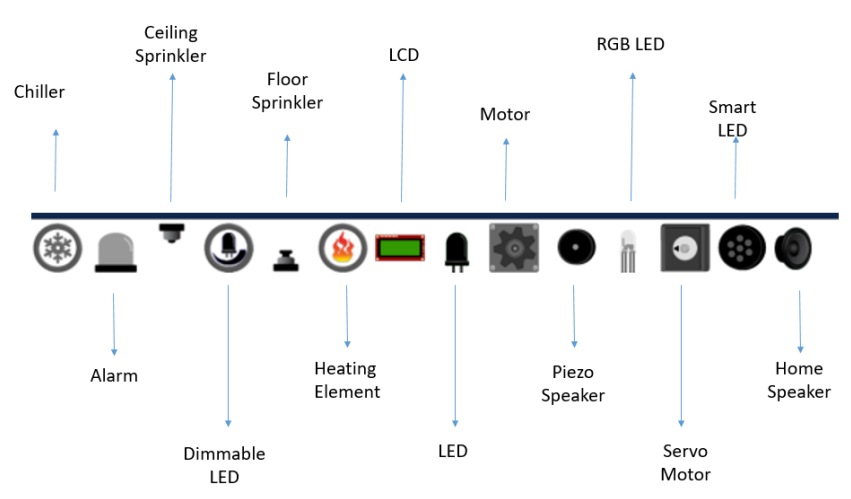

Fig. 5. Actuators in simulation software

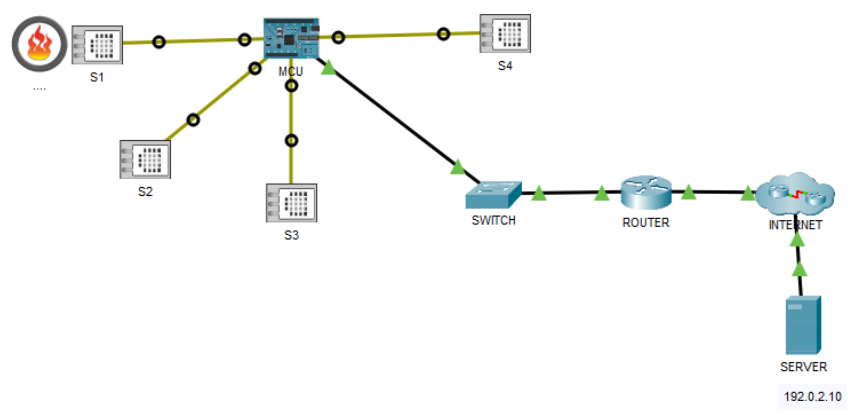

Fig. 6. Simulation topology for M2M communication scenario

In the scenario, the automobile was started to create smoke and it was evaluated whether the simulation worked correctly. In this simulation automation system, the reaction of the automation system can also be followed when the smoke level is above certain units. As shown Figure 11, the IoT Home Gateway hardware provides control from the web interface (192.168.25.1 in the example).

Accordingly, if the status of the solar panel is below $1 \mathrm{Wh}$ or the battery is below $20 \%$, the lamp will be half opened and the window will be opened.

\section{CONCLUSION}

IoT solutions, which are developed for humans use contribute to building large networks of IoT devices, reducing complexity, enabling device efficiency, and driving innovation among industries seeking operational efficiency. IoT solutions cover everything IoT device designers, software developers, and product manufacturers need to develop and implement IoT ideas, including hardware IP and software platforms. End-toend security, multiple workloads, secure network systems, and cyber-security measures developed using artificial intelligence methods are effectively used in IoT solutions. Since the physical realization of all these systems requires high cost, simulation tools are used effectively.

Simulations are tools that can be used in situations that may be difficult or dangerous to do in the real world and help understand how the real environment works. Simulations are used to develop the first proof of concept of the research life cycle. They are also very useful tools that allow you to analyze the behavior of a system by making changes in parameters, eliminating various additional tasks that are not directly related to the purpose in the real environment. While developing IoT solutions, working with simulation software before prototyping prevents unnecessary waste of time and helps to detect possible error situations in advance. In this study, various IoT solution examples were introduced using Cisco Packet Tracer 8.0 simulation software and IoT Supported Home Automation Systems were developed with sample scenarios. Softwareready Python, Java Script or block-based code keeps the attention focused directly on the IoT solution. In this study, analysis of network traffic and bandwidth consumption is not examined. Depending on the number of IoT devices, new scenarios can be developed using such criteria. 


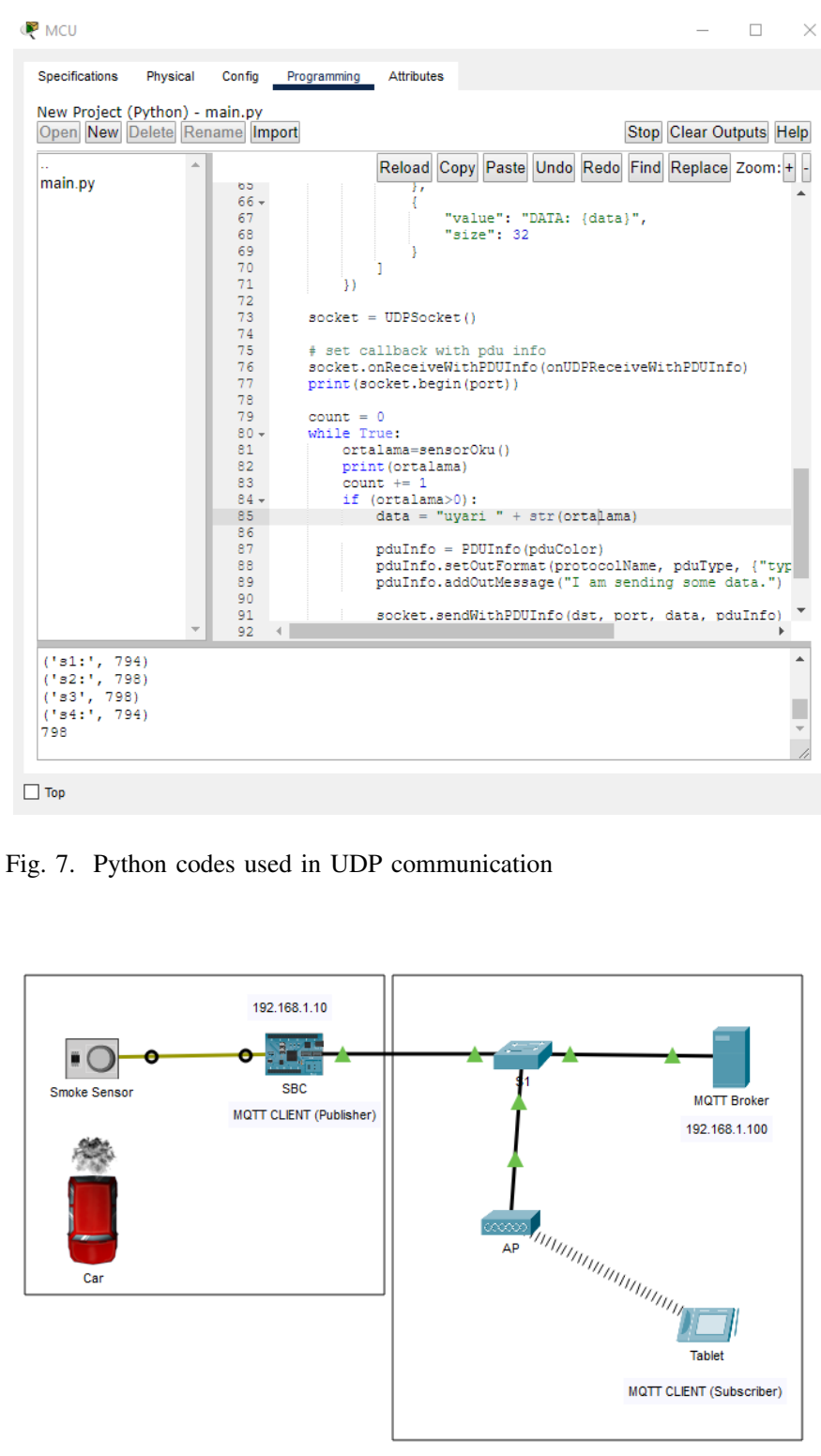

Fig. 8. Simulation topology for the MQTT sample

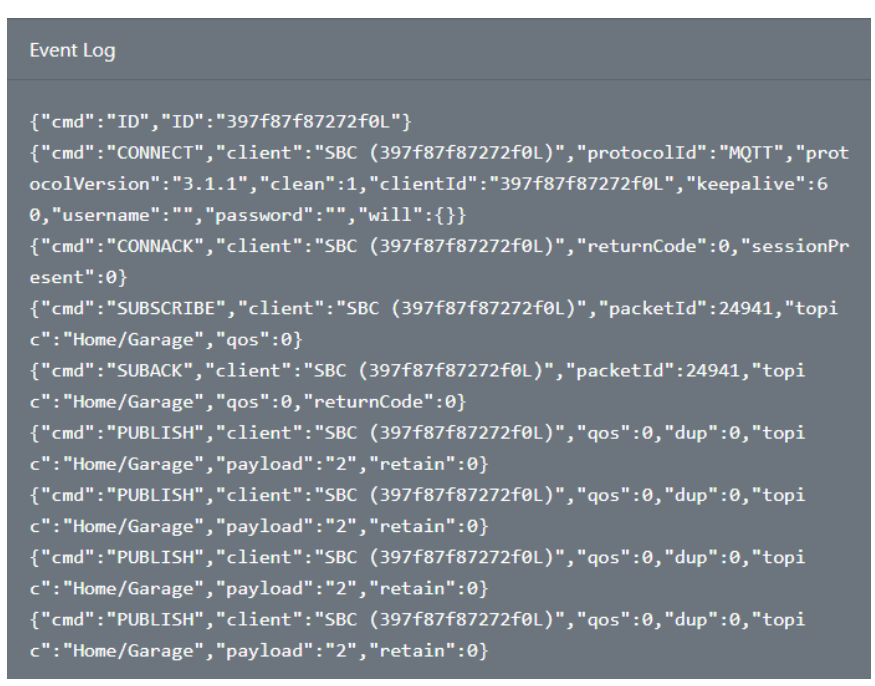

Fig. 9. Client side view of messages received from MQTT broker
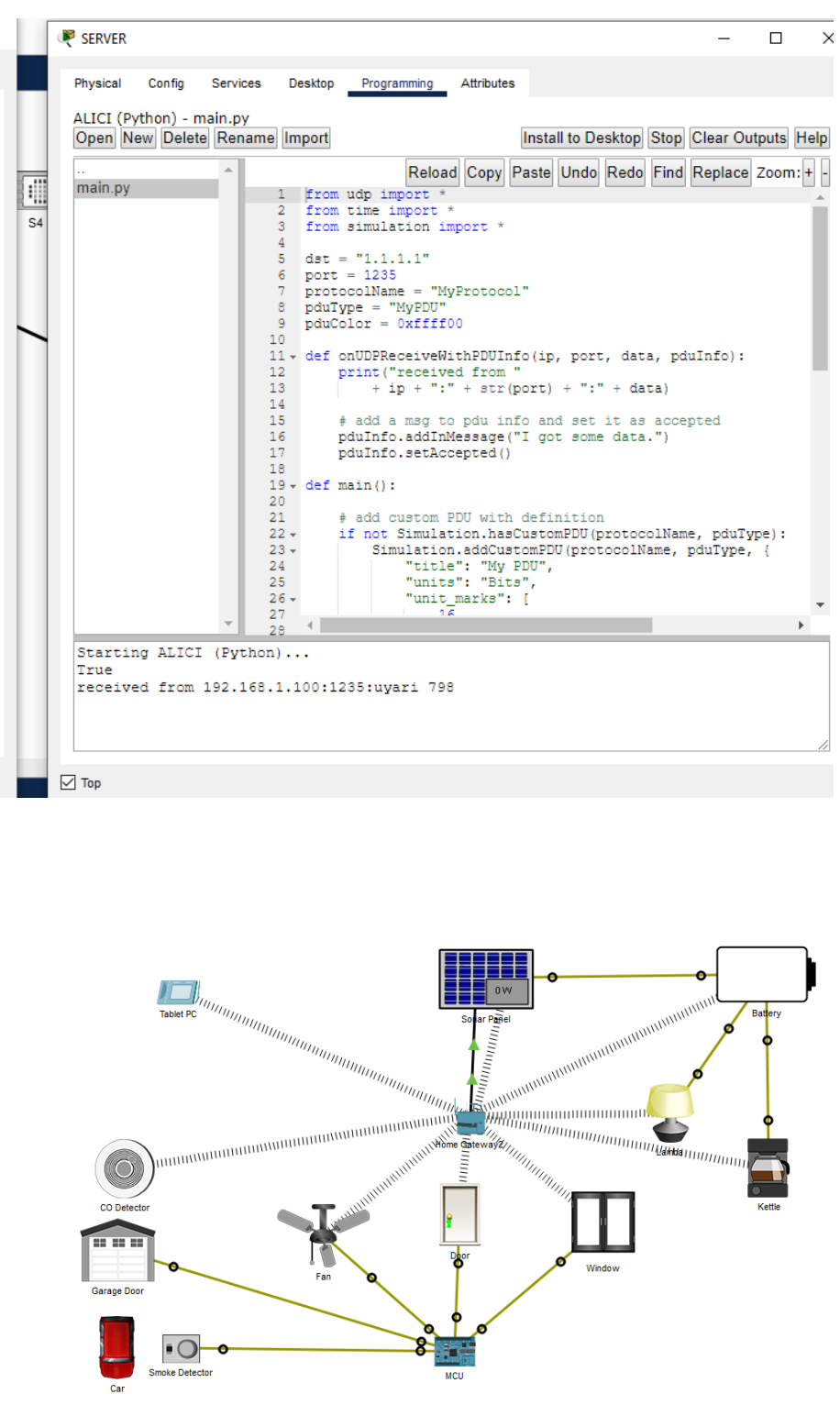

Fig. 10. IoT Gateway solution topology

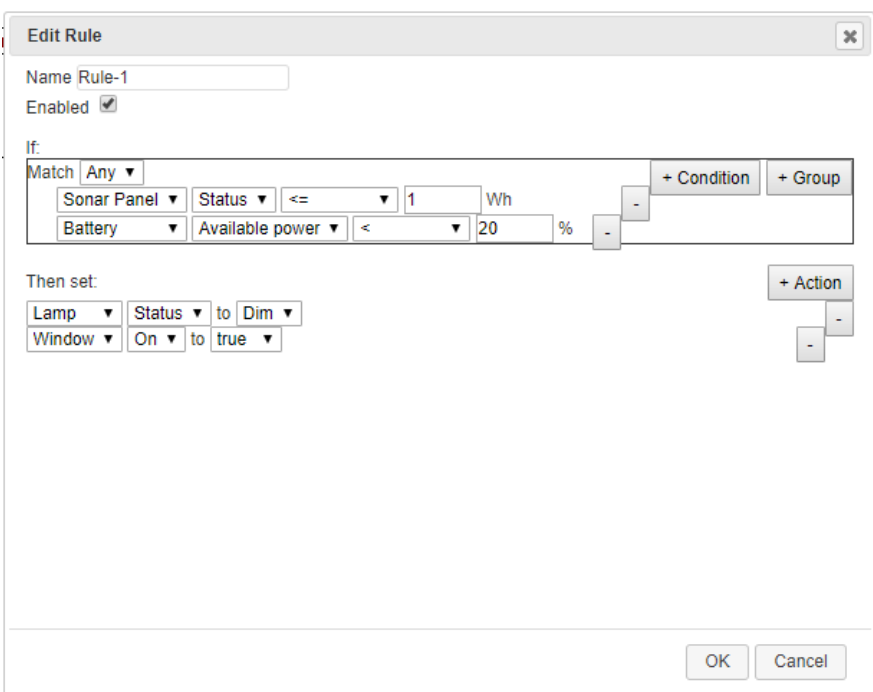

Fig. 11. IoT Gateway automation configuration from the web interface 


\section{REFERENCES}

[1] M. Stoyanova, Y. Nikoloudakis, S. Panagiotakis, E. Pallis, and E. K. Markakis, "A Survey on the Internet of Things (IoT) Forensics: Challenges, Approaches, and Open Issues," IEEE Communications Surveys and Tutorials, vol. 22, no. 2, pp. 1191-1221, 2020.

[2] M. Chernyshev, Z. Baig, O. Bello, and S. Zeadally, "Internet of things (IoT): Research, simulators, and testbeds," IEEE Internet of Things Journal, vol. 5, no. 3, pp. 1637-1647, jun 2018.

[3] G. Tuna and R. Daş, "Wireless sensor network-based health monitoring system for the elderly and disabled," International Journal of Computer Networks and Applications, vol. 2, no. 6, pp. 247253, 2015. [Online]. Available: http://www.ijcna.org/issues.php?vol=2\& issue $=6 \mathrm{http}: / /$ files $/ 107 / \mathrm{Vol}-2$-issue-6-M-02.pdf

[4] R. Das, G. Tuna, and A. Tuna, "Design and implementation of a smart home for the elderly and disabled," International Journal of Computer Networks and Applications, vol. 2, no. 6, pp. 242 246, 2015. [Online]. Available: http://www.ijcna.org/issues.php?vol=2\& issue $=6 \mathrm{http}: / /$ files $/ 109 / \mathrm{Vol}-2$-issue $-6-\mathrm{M}-01 . \mathrm{pdf}$

[5] R. Das, A. Tuna, S. Demirel, and M. K. Yurdakul, "A survey on the internet of things solutions for the elderly and disabled: Applications, prospects, and challenges," International Journal of Computer Networks And Applications, vol. 4, no. 3, pp. 84-92, jan 2017. [Online]. Available: http://www.ijcna.org/Manuscripts/IJCNA-2017-O-08.pdfhttp: //files/111/IJCNA-2017-O-08.pdf

[6] I. I. Pătru, M. Carabaş, M. Bărbulescu, and L. Gheorghe, "Smart home IoT system," Networking in Education and Research: RoEduNet International Conference 15th Edition, RoEduNet 2016 - Proceedings, 2016.

[7] T. Malche and P. Maheshwary, "Internet of Things (IoT) for building smart home system," in 2017 International Conference on I-SMAC (IoT in Social, Mobile, Analytics and Cloud), 2017, pp. 65-70.

[8] H. Singh, V. Pallagani, V. Khandelwal, and U. Venkanna, "IoT based smart home automation system using sensor node," Proceedings of the 4th IEEE International Conference on Recent Advances in Information Technology, RAIT 2018, pp. 1-5, 2018.

[9] W. A. Jabbar, M. H. Alsibai, N. S. S. Amran, and S. K. Mahayadin, "Automation System for Smart Home," 2018 International Symposium on Networks, Computers and Communications (ISNCC), pp. 1-6, 2018.

[10] F. Yalcinkaya, H. Aydilek, M. Y. Erteen, and I. Nihat, "IoT based Smart Home Testbed using MQTT Communication Protocol," Uluslararasl Muhendislik Arastirma ve Gelistirme Dergisi, p. 317, 2020.

[11] Y. Kocyigit and Ö. Sine, "İnternet Üzerinden Kontrol Edilen Tam Otomasyonlu Akıllı Ev Sistemleri Için Örnek Bir Uygulama," DÜMF Mühendislik Dergisi, vol. 11, no. 2, pp. 521-532, 2020.

[12] H. Gunes, S. Bicakci, E. Orta, and D. Akdas, "Akıllı evlerde kullanılan yapay zekâ teknikleri için simülasyon geliştirilmesi," Gazi Üniversitesi Fen Bilimleri Dergisi Part C: Tasarım ve Teknoloji, vol. 7, no. 3, pp. 554-563, 2019.

[13] A. Eleyan and J. Fallon, "IoT-based home automation using android application," 2020 International Symposium on Networks, Computers and Communications, ISNCC 2020, pp. 3-6, 2020.

[14] M. Assim and A. Al-Omary, "Design and Implementation of Smart Home using WSN and IoT Technologies," 2020 International Conference on Innovation and Intelligence for Informatics, Computing and Technologies, 3ICT 2020, 2020.

[15] A. Ozturk and N. Sepanta, "Akilli ESistemlerinde KullanilanYöntemlerin Farklari, Avantajlari Ve Dezavantajlari," Istanbul Aydin Universitesi Dergisi, vol. 9, no. 4, pp. 115-125, 2017.

[16] P. Sethi and S. R. Sarangi, "Internet of Things: Architectures, Protocols, and Applications," Journal of Electrical and Computer Engineering, vol. 2017, p. 25, 2017.

[17] P. Sivagami, D. Jamunarani, P. Abirami, M. Pushpavalli, V. Geetha, and R. Harikrishnan, "Smart Home Automation System MethodologiesA Review," in 2021 Third International Conference on Intelligent Communication Technologies and Virtual Mobile Networks (ICICV). IEEE, feb 2021, pp. 1386-1390. [Online]. Available: https://ieeexplore. ieee.org/document/9388491/

[18] L. Dürkop, B. Czybik, and J. Jasperneite, "Performance evaluation of M2M protocols over cellular networks in a lab environment," 2015 18th International Conference on Intelligence in Next Generation Networks, ICIN 2015, pp. 70-75, 2015.

[19] E. Ozdogan and O. A. Erdem, "Nesnelerin İnterneti İçin Hibrit Uygulama Katmanı Protokol Tasarımı," Mühendislik Bilimleri ve Tasarım Dergisi, vol. 8, no. 1, pp. 285-304, mar 2020. [Online]. Available: https://dergipark.org.tr/tr/doi/10.21923/jesd.530295
[20] A. Talaminos-Barroso, M. A. Estudillo-Valderrama, L. M. Roa, J. Reina-Tosina, and F. Ortega-Ruiz, "A Machine-to-Machine protocol benchmark for eHealth applications - Use case: Respiratory rehabilitation," Computer Methods and Programs in Biomedicine, vol. 129, pp. 1-11, 2016. [Online]. Available: https://www.sciencedirect.com/science/article/pii/S0169260715302959

[21] Edited by Andrew Banks and Rahul Gupta, "MQTT Version 3.1.1," 2014. [Online]. Available: http://docs.oasis-open.org/mqtt/mqtt/v3.1.1/ mqtt-v3.1.1.html

[22] R. Herrero, "Analytical model of IoT CoAP traffic," Digital Communications and Networks, vol. 5, no. 2, pp. 63-68, 2019.

[23] A. Keranen, M. Kovatsch, and K. Hartke, "RESTful Design for Internet of Things Systems," 2017. [Online]. Available: https: //tools.ietf.org/id/draft-keranen-t2trg-rest-iot-05.htm

[24] H. Luo, C. Wang, H. Luo, F. Zhang, F. Lin, and G. Xu, "G2F: A Secure User Authentication for Rapid Smart Home IoT Management," IEEE Internet of Things Journal, vol. XX, no. XX, pp. 1-12, 2021.

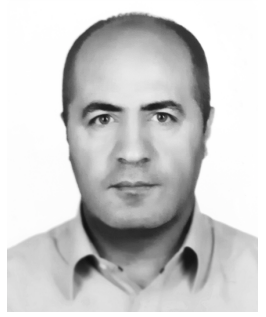

Erdal Ozdogan graduated B.Sc. degree from Ankara University Astronomy and Space Science in 2000, and a second B.Sc. degree, from Anadolu University Management Information Systems in 2019, Turkey. He graduated with his master's degree from Gazi University, Department of Computer Science in 2012, and his Ph.D. in 2020 at the Department of Information Systems. He serves instructor training to public institutions and organizations about computer networks, cybersecurity, and IoT at the Cisco Networking Academy.

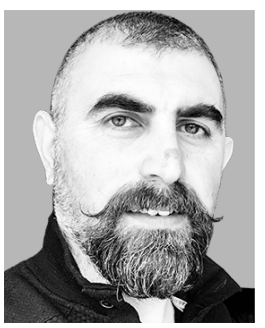

Resul Das is a full professor in the Department of Software Engineering at the University of Firat, where he has been a faculty member since 2011 . From 2000 to 2011 he served as both instructor and network administrator at the Department of Informatics at the Firat University. He has been the instructor and the coordinator of the Cisco Networking Academy Program since 2002 at this university. $\mathrm{He}$ graduated with B.Sc. and M.Sc. degrees from the Department of Computer Science at the Firat University in 1999 and 2002 respectively. Then he completed his Ph.D. degree at the Department of Electrical-Electronics Engineering at the same university in 2008 . He also worked between September 2017 and June 2018 as a visiting professor at the Department of Computing Science at the University of Alberta, Edmonton, Canada. He has authored more than a hundred papers in international conference proceedings and also he has been serving as Associate Editor for the Journal of IEEE Access and the Turkish Journal of Electrical Engineering and Computer Science. His current research areas include computer networks and network security, cybersecurity, software design and architecture, IoT/M2M applications, knowledge discovery, and data fusion. 